\title{
Article \\ Multiple Symmetric Lipomatosis: A Cross-Sectional Study to Investigate Clinical Features and Patients' Quality of Life
}

\author{
Daniel Schiltz ${ }^{1}$ (D), Karolina Mueller ${ }^{2}$, Christine Ortner ${ }^{3}$, Sebastian Tschernitz ${ }^{3}$, Alexandra Anker ${ }^{1}$, \\ Oliver Felthaus ${ }^{1}$ (D) Julia Schreml ${ }^{4}$, Michael Koller ${ }^{2}$, Lukas Prantl ${ }^{1}$ (D) and Stephan Schreml ${ }^{3, *(D)}$ \\ 1 Department of Plastic, Hand- and Reconstructive Surgery, University Hospital Regensburg, \\ 93053 Regensburg, Germany; schiltz.da@gmail.com (D.S.); alexandra.anker@ukr.de (A.A.); \\ oliver.felthaus@ukr.de (O.F.); lukas.prantl@ukr.de (L.P.) \\ 2 Center for Clinical Studies, University Hospital Regensburg, 93053 Regensburg, Germany; \\ karolina.mueller@ukr.de (K.M.); michael.koller@ukr.de (M.K.) \\ 3 Department of Dermatology, University Hospital Regensburg, 93053 Regensburg, Germany; \\ ch.ortner@salus-klinik.de (C.O.); sebastian.tschernitz@kssg.ch (S.T.) \\ 4 Institute of Human Genetics, University Hospital of Cologne, 50937 Köln, Germany; Julia@schreml.de \\ * Correspondence: stephan.schreml@ukr.de; Tel.: +49-(0)-941-944-9603
}

Citation: Schiltz, D.; Mueller, K.; Ortner, C.; Tschernitz, S.; Anker, A.; Felthaus, O.; Schreml, J.; Koller, M.; Prantl, L.; Schreml, S. Multiple Symmetric Lipomatosis: A Cross-Sectional Study to Investigate Clinical Features and Patients' Quality of Life. Symmetry 2021, 13, 1823. https://doi.org/10.3390/ sym 13101823

Academic Editors: John H. Graham and Zongjin Lin

Received: 31 August 2021

Accepted: 28 September 2021

Published: 30 September 2021

Publisher's Note: MDPI stays neutral with regard to jurisdictional claims in published maps and institutional affiliations.

Copyright: (c) 2021 by the authors. Licensee MDPI, Basel, Switzerland. This article is an open access article distributed under the terms and conditions of the Creative Commons Attribution (CC BY) license (https:/ / creativecommons.org/licenses/by/ $4.0 /)$.
Abstract: Within the subcutaneous adipose tissue diseases, multiple symmetric lipomatosis (MSL) (syn.: Launois Bensaude Syndrome, Morbus Madelung, benign symmetric lipomatosis) is rare. The pathogenesis of MSL remains unclear. We investigated the largest German cohort of MSL patients to obtain anamnestic data and quality of life with a standard questionnaire. Twenty-nine patients with confirmed MSL were included and filled in a questionnaire designed for this study. The questionnaire assessed common anamnestic factors, such as quality of life (EQ-5D-3L) and subjective treatment goals and success ("Patient-Benefit-Index-Lymphedema", PBI-L). The gender distribution of the patients involved in the study was m/f: $1 / 4$ (male: $n=6$ (21\%); female $n=23$ $(79 \%))$. While the exact pathophysiology of MSL remains unclear, a subset of patients' positive family history suggests a strong genetic factor, sometimes compatible with autosomal dominant inheritance. Patients with MSL showed lower health states (EQ VAS Score: $m=51$, sd $=24$, range $=0-90$ ) than the German norm population $(\mathrm{m}=77)$. Around two thirds $(68 \%)$ of patients reported relevant benefits of therapy (liposuction/lipectomy). In our cohort about one third of the patients reported a positive family history for MSL-like features. Additionally, at least in some patients, a strong genetic factor, compatible with autosomal dominant inheritance, seems a possible major driver of MSL development. Alcohol consumption and MSL development has to be regarded as a controversial issue. Patients suffering from MSL have a clear decrease in quality of life and a marked wish for treatment.

Keywords: multiple symmetric lipomatosis (MSL); Morbus Madelung; Launois Bençaude; benign symmetric lipomatosis (BSL); quality of life in MSL

\section{Introduction}

Within the family of subcutaneous adipose tissue diseases, multiple symmetric lipomatosis (MSL) (syn.: Launois Bensaude Syndrome, Morbus Madelung, benign symmetric lipomatosis) is rare. It is defined as a symmetric disorder of non-encapsulated adipose tissue growth [1] with a prevalence indicated as 1:25,000 [2,3]. The male to female ratio is unclear and ranges from male:female 15-30:1 to 1:2,5-6 in the current literature [3-8].

Diagnosis is established through physical examination and medical history. To describe the phenotype, several classifications are used in the literature. The first classification was described in 1991 by Donhauser and distinguishes between four types of MSL [9]. In contrast, a newer and more precise classification recently published by our research team [3] characterizes five types of MSL (Figure 1). 


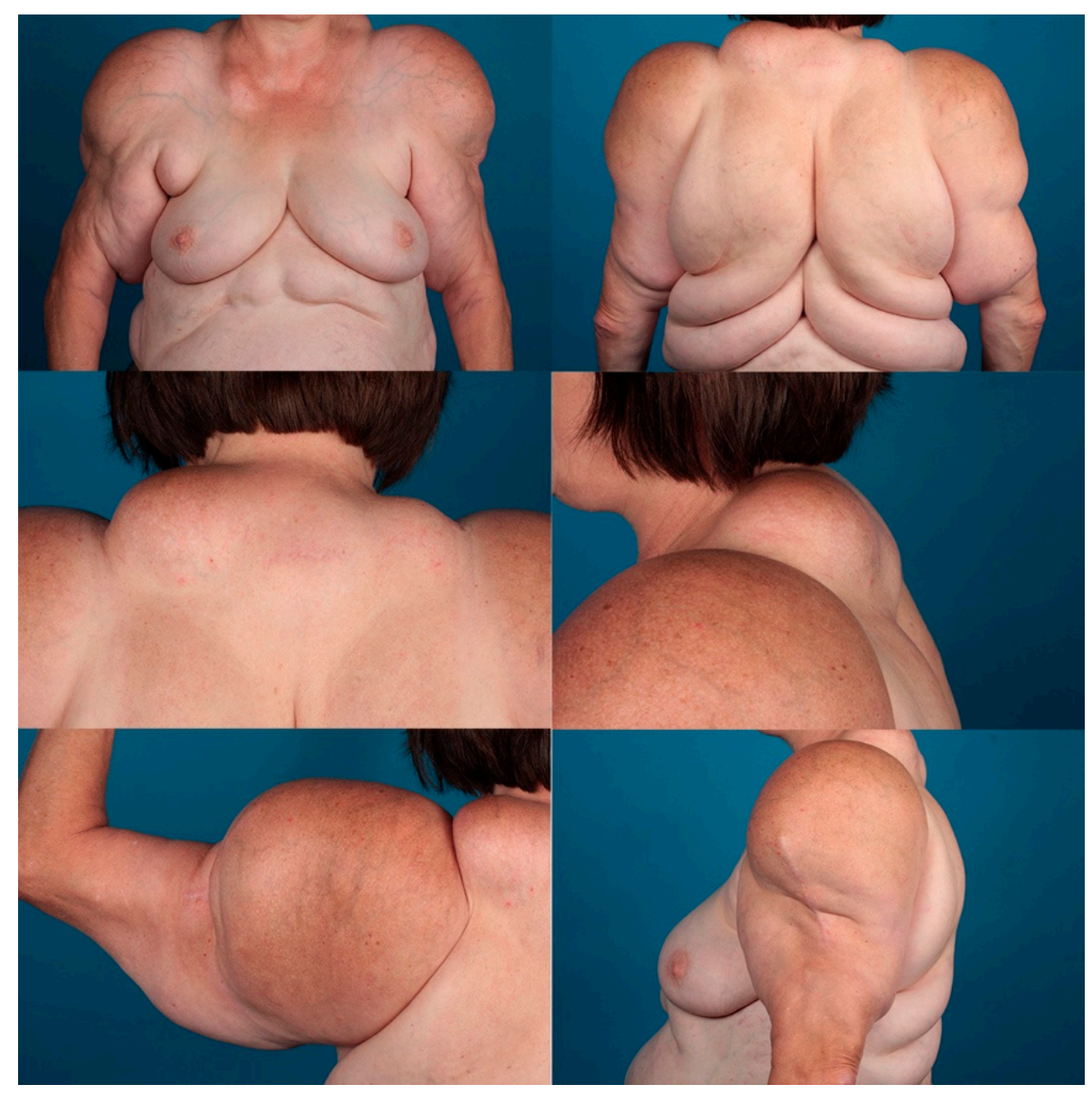

Figure 1. Phenotype of a patient suffering from MSL type Ic.

Although several roads have been taken to elucidate the cause and pathophysiology of MSL, many questions remain unanswered, including those of morbidity and quality of life. Hyperinsulinemia, hyperlipoproteinemia, hypothyroidism, hyperuricemia, renal tubular acidosis, neuropathy and myopathy have been described in association with MSL [3,10-15] Furthermore, neurological multisystem manifestation seems to be common in MSL patients [16]. This might be also due to the fact that phenotypically typical MSL adipose tissue features have been observed in patients with different defined myopathic/neuropathic syndromes (e.g., in patients with CMT or MERRF related mutations). The question as to whether there is an increased risk for myopathy/neuropathy in all MSL patients or only in a subset of patients has not fully been answered yet. An association between alcohol consumption and (sporadic) MSL remains controversial [3,6,16,17]. Sudden death and autonomous nerve affection have been reported and expanded the list of possible related diseases and complications [18]. Apart from mitochondrial inheritance, which explains some of the cases associated with myopathic and neuropathic symptoms, there are only a few reports of familial MSL cases. Some of these indicate a monogenic cause inherited in an autosomal dominant manner (possibly with reduced penetrance). Other studies found mutations in LIPE and MFN2 as monogenic autosomal recessive causes of MSL [19,20]. Recently, down-regulation of CAPSL protein was found in immunohistochemistry of adipose tissue from familial and sporadic MSL cases whereas LIPE and MFN2 stainings did not show relevant changes in expression [21]. Up-regulation of UCP1 and CD200 was shown by different groups and poses the question of whether adipose tissue in multiple symmetric lipomatosis might be derived from brown/beige fat $[22,23]$. Compared with normal tissue, the proliferation and differentiation of adipose tissue derived stem cells from lipomatous tissue decreases after mTOR pathway inhibition [24]. 
Taken together, these molecular genetic and functional findings could, if corroborated by increasing the number of patients and refinement of the immunohistological investigations, potentially serve as first diagnostic tools in MSL clinical care. Another spark of hope could be long non-coding RNAs. It has been shown that (lncRNAs) are widely expressed and have key roles in gene regulation [25]. They indirectly affect gene expression in diverse biological and physiopathological contexts and might play a role in MSL pathogenesis and could, if identifies serve as evidence for the disease.

As there is little knowledge about disease burden and common factors in the medical history of MSL patients, the purpose of the present study was to obtain precise medical history and clinical data with a standard questionnaire. We investigated, to our knowledge, the largest German cohort of MSL patients to date, treated at the University Hospital Regensburg.

\section{Materials and Methods}

In order to assess common anamnestic factors, the impact of MSL on quality of life, and therapy success, a prospective, observational, cross-sectional study was conducted. The study was approved by the Ethics Committees of the Universities of Regensburg (reference number:14-101-138). The patients in this manuscript have given written informed consent to the publication of their case details.

Inclusion criteria were confirmed diagnosis of MSL and voluntary participation. In the database of the University Hospital Regensburg, Germany, 64 patients with diagnosed MSL were found. From May to July 2017, these patients were contacted (either by phone or post) and invited to come for clinical reevaluation and diagnostic confirmation. MSL diagnosis could be confirmed for 45 of these 64 patients: 26 cases confirmed by photographs in the database and 19 cases by reevaluation in our clinic. Diagnosis was conducted by considering the morphological characteristics (disproportionate hypertrophic symmetric fat tissue growth of MSL-typical areas) and anamnesis [3]. 29 (64\%) of the 45 patients with confirmed MSL diagnosis participated in the study (Figure 2).

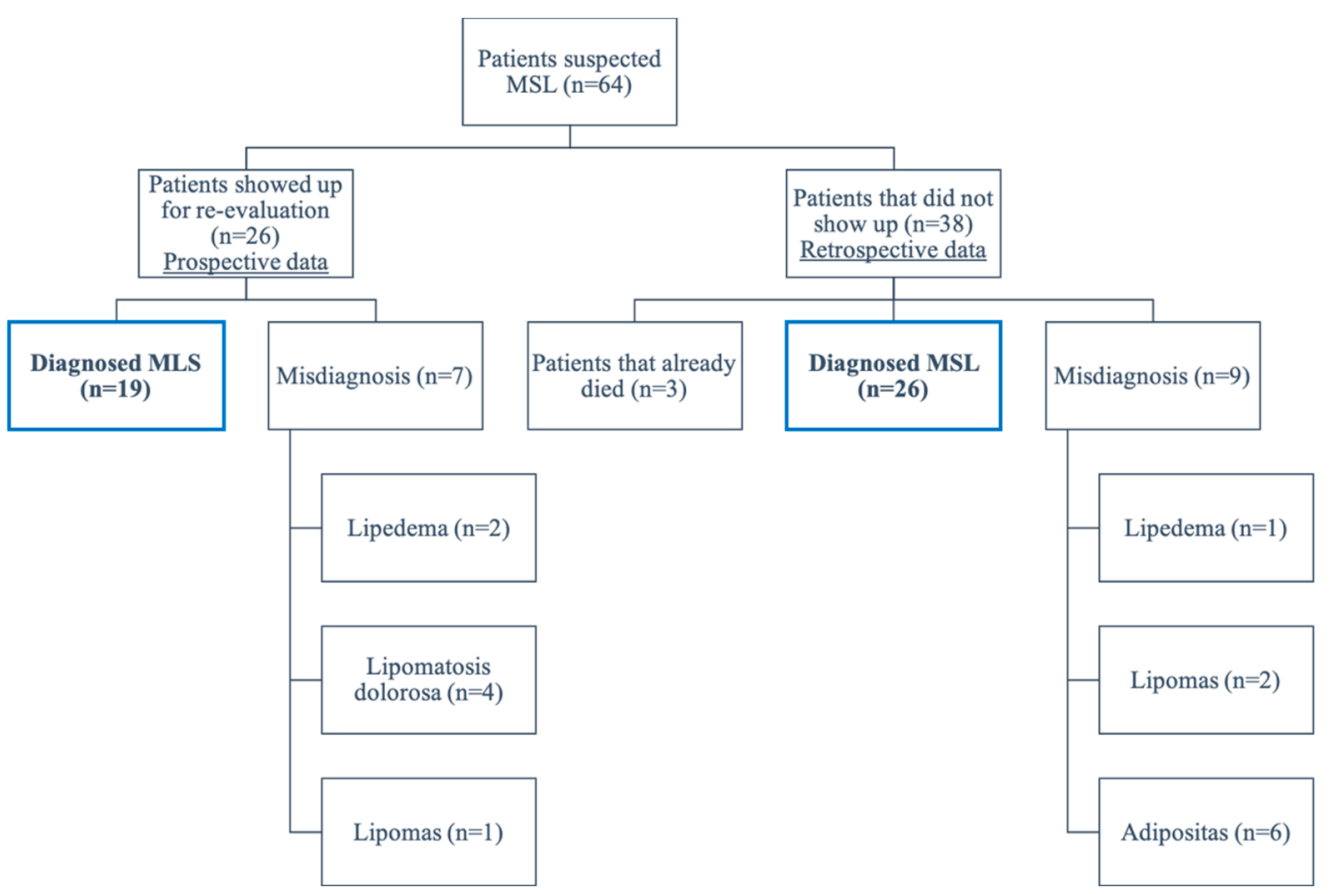

Figure 2. Flow-chart of patient inclusion in the study.

\subsection{Questionnaire}

A questionnaire specifically designed for this study was sent to the patients either by post or by email. The questionnaire contained questions regarding clinical information and patient-reported outcome measures (PROMs). 


\subsubsection{Clinical Information}

In addition to general data about height, bodyweight and gender, we assessed the age of disease onset, weight changes, and parameters such as pain and paresthesia in the affected areas. Further categories assessed were comorbidities and medication, risk factors, data about family-history, and therapy evolution.

\subsubsection{Patient-Reported Outcomes}

To assess quality of life, the "EQ-5D-3L" [26] was included in the questionnaire. Scoring was performed according to the official "EQ-5D-3L"guidelines [27].

To evaluate patient-relevant therapy benefits, we included the "Patient-Benefit-IndexLymphedema" (PBI-L) [28]. Patients retrospectively rated the importance and achievement of treatment goals on the same day. Therapy was liposuction and/or lipectomy and was performed by the department of plastic surgery at University Hospital Regensburg. Scoring was done according the official PBI guidelines [29].

\subsection{Statistical Analyses}

Descriptive statistics included counts (n), percentages (\%), means (m) and standard deviation (sd). IBM SPSS Statistics 25.0 (IBM Corporation, Armonk, NY, USA) was the statistical analysis tool.

\section{Results}

\subsection{Clinical Information}

A total of 45 questionnaires were sent to all 45 patients with confirmed MSL diagnosis. 29 questionnaires (64\%) were returned. The mean age of the patients who responded was 59 years ( $\mathrm{sd}=13$, range: $31-77$ years). The sex ratio was $\mathrm{m} / \mathrm{f}: 1 / 4$ (male: $\mathrm{n}=6(21 \%)$; female $\mathrm{n}=23(79 \%))$. An overview of general data is shown in Table 1 .

Table 1. General data.

\begin{tabular}{ll}
\hline Age in years mean $\pm(\min -\max ) \mathrm{n}=29$ & $58.5 \pm 13(31-77)$ \\
\hline Sex & $6(21 \%)$ \\
$\quad$ male & $23(79 \%)$ \\
$\quad$ female & $88.9 \pm 21(53-130)$ \\
\hline Weight in kg mean $\pm($ min-max $) \mathrm{n}=27$ & \\
\hline Occupation & $1(3 \%)$ \\
Trainee & $13(45 \%)$ \\
Employee & $3(10 \%)$ \\
Civil servant & $2(7 \%)$ \\
Freelancer & $1(3 \%)$ \\
Househusband $/$ housewife & $2(7 \%)$ \\
Pensioner & $7(24 \%)$ \\
Missing & $164.9 \pm 8(148-188)$ \\
\hline Height in cm mean $\pm($ min-max) $\mathrm{n}=29$ & $32 \pm 8(21-53)$ \\
\hline Body-Mass-Index (BMI) in $\mathrm{kg} / \mathrm{m}^{2}$ mean \pm & $4(14 \%)$ \\
(min-max) $\mathrm{n}=27$ & $8(28 \%)$ \\
Normal weight & $4(14 \%)$ \\
Overweight & $8(28 \%)$ \\
Adipositas I (BMI 30-35) & $3(10 \%)$ \\
Adipositas II (BMI 35-40) & $2(7 \%)$ \\
Adipositas III (BMI $>40)$ & \\
Missing & \\
\hline
\end{tabular}


Table 1. Cont.

\begin{tabular}{ll}
\hline Weight changes in $\mathrm{kg}$ in last 5 years & $14(48 \%)$ \\
Stable & $13(45 \%)(16 \pm 12,2-30)$ \\
Weight gain (mean $\pm \mathrm{sd}$, min-max) & $1(3 \%)(7)$ \\
Weight loss (mean) & $1(3 \%)$ \\
$\quad$ Missing & $23(79 \%)$ \\
\hline $\begin{array}{l}\text { Permanent medication } \\
\text { Yes }\end{array}$ & $6(21 \%)$ \\
$\quad$ No & $2 \pm 2(0-4)$ \\
\hline Comorbidities mean \pm (min-max) & \\
Yes & $27(93 \%)$ \\
(hypertension $\mathrm{n}=15$, diabetes mellitus $\mathrm{n}=3$, & \\
hyperlipidemia $\mathrm{n}=7$, myasthemia $\mathrm{n}=5$, & \\
depression $\mathrm{n}=8$, & $2(7 \%)$ \\
other disease $\mathrm{n}=19)$ & \\
$\quad$ No & $5(17 \%)$ \\
\hline Alcohol consumption & $7(24 \%)$ \\
$\quad$ Yes, daily & $17(59 \%)$ \\
$\quad$ Yes, not daily & \\
$\quad$ No &
\end{tabular}

The mean age at MSL onset was 37 years ( $\mathrm{sd}=15$, range: $14-70$ years). The mean body-mass-index was $32 \mathrm{~kg} / \mathrm{m}^{2}\left(\mathrm{sd}=8\right.$, range: $\left.21-53 \mathrm{~kg} / \mathrm{m}^{2}\right)$. The patient's weight was stable in the last five years in $48 \%(\mathrm{n}=14)$ of the patients. $45 \%(\mathrm{n}=13)$ declared a weight gain. Of those who gained weight, the mean weight gain was $16 \mathrm{~kg}(\mathrm{sd}=12$, range: $2-30 \mathrm{~kg})$ in the last five years. The body areas affected by weight gain are shown in Figure 3. Most patients stated volume increase on the upper legs ( $\mathrm{n}=12 ; 92 \%$ of 13 patients), upper arms ( $\mathrm{n}=10 ; 77 \%$ of 13 patients), and hips \& buttocks ( $\mathrm{n}=10,77 \%$ of 13 patients). Of all the patients, some ( $\mathrm{n}=8,28 \%$ of 29 patients) reported a suspected factor which had triggered the MSL. In 25\% $(n=2)$ of these cases, a surgical procedure was reported preceding MSL occurrence. One patient said that alcohol withdrawal preceded the onset of MSL. Table 2 presents disease specific data.

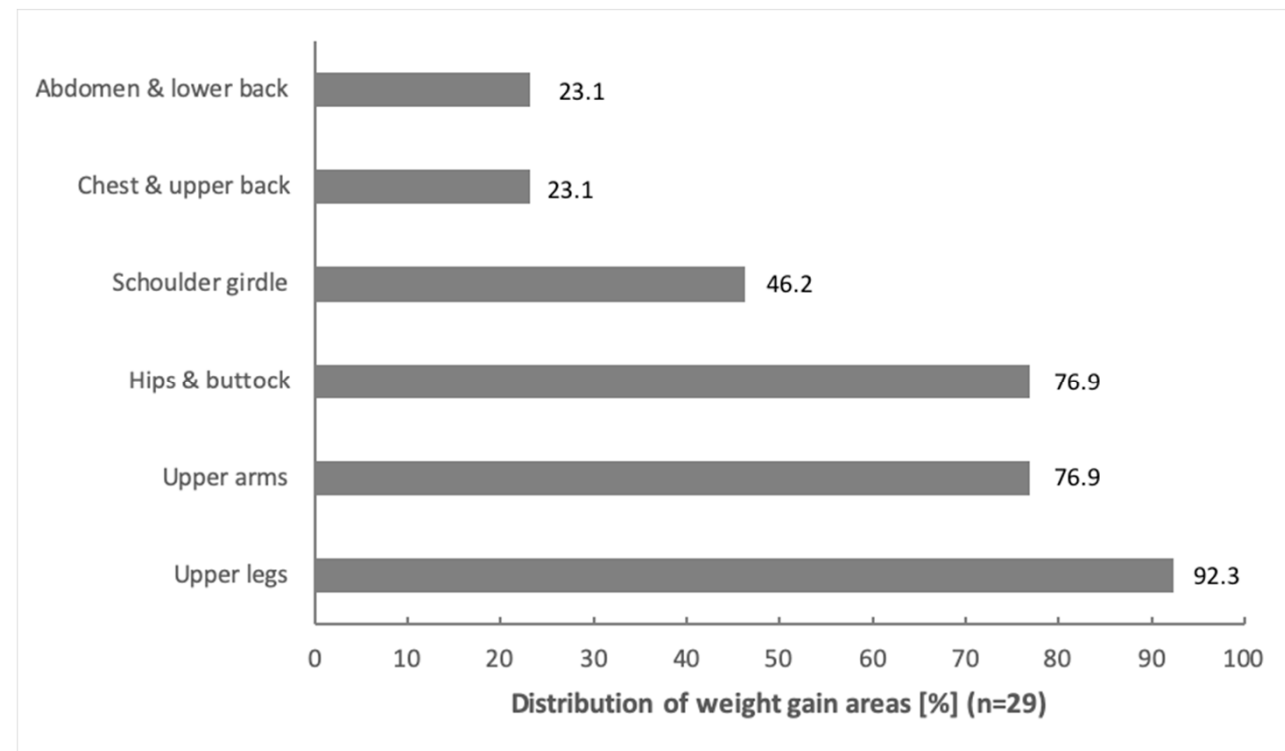

Figure 3. Distribution of weight gain areas. 
Table 2. Disease specific data.

\begin{tabular}{|c|c|}
\hline Age of MSL onset in years mean $\pm(\min -\max ) n=29$ & $37.0 \pm 15(14-70)$ \\
\hline \multicolumn{2}{|l|}{ Pain } \\
\hline \multicolumn{2}{|l|}{ Pain in affected areas } \\
\hline Yes & $8(28 \%)$ \\
\hline No & $21(72 \%)$ \\
\hline \multicolumn{2}{|l|}{ Factors that ease pain } \\
\hline \multicolumn{2}{|l|}{ Yes } \\
\hline (movement $n=5$, cold $n=3$, warmth $n=4$, lymphatic & $11(38 \%)$ \\
\hline \multicolumn{2}{|l|}{ drainage $n=1$, physiotherapy $n=2$, massage $n=1$ ) } \\
\hline No & $17(59 \%)$ \\
\hline Missing & $1(3 \%)$ \\
\hline \multicolumn{2}{|l|}{ Factors that increase pain } \\
\hline \multicolumn{2}{|l|}{ Yes } \\
\hline (movement $\mathrm{n}=3$, cold $\mathrm{n}=4$, warmth $\mathrm{n}=3$, long time & $15(52 \%)$ \\
\hline \multicolumn{2}{|l|}{ standing $n=3)$} \\
\hline No & $14(48 \%)$ \\
\hline \multicolumn{2}{|l|}{ Paraesthesia in affect areas } \\
\hline Yes & $18(62 \%)$ \\
\hline No & $10(34 \%)$ \\
\hline Missing & $1(3 \%)$ \\
\hline \multicolumn{2}{|l|}{ Suspected factor in the last 6 months that triggered MSL } \\
\hline \multicolumn{2}{|l|}{$\begin{array}{l}\text { Yes } \\
\text { (diverticulosis }+ \text { surgery } n=1 \text {, oral contraceptives } n=1 \text {, }\end{array}$} \\
\hline & $8(28 \%)$ \\
\hline \multicolumn{2}{|l|}{$\begin{array}{l}\text { pregnancy (clomifen) } n=1 \text {, stress } n=1 \text {, increasing insulin } \\
\text { resistance } \mathrm{n}=1 \text { ) }\end{array}$} \\
\hline No & $19(66 \%)$ \\
\hline Missing & $2(7 \%)$ \\
\hline \multicolumn{2}{|l|}{ Family occurrence } \\
\hline Yes & $10(34 \%)$ \\
\hline No & $10(34 \%)$ \\
\hline Unknown & $8(28 \%)$ \\
\hline Missing & $1(3 \%)$ \\
\hline \multicolumn{2}{|l|}{ Therapy } \\
\hline Yes & $23(79 \%)$ \\
\hline \multicolumn{2}{|l|}{ (liposuction $n=16$, lipectomy $n=7$ ) } \\
\hline \multicolumn{2}{|l|}{ Number of treatments } \\
\hline 1 & $7(24 \%)$ \\
\hline 2 & $8(28 \%)$ \\
\hline 3 & $3(10 \%)$ \\
\hline 4 & $4(14 \%)$ \\
\hline 5 & $1(3 \%)$ \\
\hline No & $6(21 \%)$ \\
\hline
\end{tabular}

Around three quarters ( $\mathrm{n}=21,72 \%)$ of all patients indicated pain in the affected areas (Table 2). One third ( $\mathrm{n}=11,38 \%)$ of the patients stated factors that ease the pain: warmth $(n=5)$, cold $(n=4)$, movement $(n=6)$. Half of the patients $(n=15,52 \%)$ indicated factors that trigger pain: warmth $(n=5)$, cold $(n=5)$, and movement $(n=6) .62 \%(n=18)$ feel paresthesia in the affected areas.

The majority $(80 \%, \mathrm{n}=23)$ were taking medication on a regular basis. There was no commonality in number and agent of the medication taken by the patients (Table 3). 
Table 3. Overview of medication of all patients.

\begin{tabular}{|c|c|c|}
\hline Medication & $\mathrm{n}$ & $\%$ \\
\hline Allopurinol & 2 & 2.4 \\
\hline Amlodipin & 2 & 2.4 \\
\hline Anastrozol & 1 & 1.2 \\
\hline ASS & 2 & 2.4 \\
\hline Bimatoprost & 1 & 1.2 \\
\hline Bisoprolol & 3 & 3.6 \\
\hline Candesartan & 2 & 2.4 \\
\hline Cetirizin & 1 & 1.2 \\
\hline Citalopram & 1 & 1.2 \\
\hline Clomipramin & 1 & 1.2 \\
\hline Coumarin & 1 & 1.2 \\
\hline Dapagliflozin & 1 & 1.2 \\
\hline Diclofenac & 1 & 1.2 \\
\hline Digoxin & 1 & 1.2 \\
\hline Diltiazem & 1 & 1.2 \\
\hline Enalapril & 2 & 2.4 \\
\hline Esomeprazol & 1 & 1.2 \\
\hline Euthyrox & 1 & 1.2 \\
\hline Ferrosanol & 1 & 1.2 \\
\hline Formoterol & 1 & 1.2 \\
\hline Furosemid & 1 & 1.2 \\
\hline Gestagen & 4 & 4.8 \\
\hline Ginkgo & 1 & 1.2 \\
\hline Hydrochlorothiazid & 1 & 1.2 \\
\hline Ibuprofen & 1 & 1.2 \\
\hline Insulin & 1 & 1.2 \\
\hline L-Thyroxin & 4 & 4.8 \\
\hline Liponsäure & 1 & 1.2 \\
\hline Lorazepam & 1 & 1.2 \\
\hline Mesalazin & 1 & 1.2 \\
\hline Metformin & 1 & 1.2 \\
\hline Methylprednisolon & 1 & 1.2 \\
\hline Metoprolol & 4 & 4.8 \\
\hline Moxonidin & 1 & 1.2 \\
\hline Naproxen & 1 & 1.2 \\
\hline Paroxetin & 1 & 1.2 \\
\hline PPI & 5 & 6.0 \\
\hline Pravastatin & 1 & 1.2 \\
\hline Pregabalin & 2 & 2.4 \\
\hline Propanolol & 1 & 1.2 \\
\hline Ramipril & 6 & 7.2 \\
\hline Raniditid & 1 & 1.2 \\
\hline Rivaroxaban & 1 & 1.2 \\
\hline Salmeterol & 2 & 2.4 \\
\hline $\begin{array}{l}\text { +Fluticasonpropionat } \\
\text { Simvastatin }\end{array}$ & 2 & 2.4 \\
\hline Thiazid + & 1 & 1.2 \\
\hline $\begin{array}{l}\text { Pyrazinkarbonylguanidin } \\
\text { Tilidin }\end{array}$ & 1 & 12 \\
\hline Timolol und Dorzolamid & 1 & $\begin{array}{l}1.2 \\
1.2\end{array}$ \\
\hline Torasemid & 2 & 2.4 \\
\hline Tyronajod & 1 & 1.2 \\
\hline Valsartan & 2 & 2.4 \\
\hline Venlafaxin & 1 & 1.2 \\
\hline Zopiclon & 1 & 1.2 \\
\hline Total & 83 & 100.0 \\
\hline
\end{tabular}


$93 \%(n=27)$ of the patients reported on comorbidities. An overview of the most common comorbidities is shown in Figure 4. More than half of the patients did not consume alcohol at all $(\mathrm{n}=17,59 \%)$ and five patients $(17 \%)$ reported daily alcohol consumption (more than 1 glass/day). About one third $(n=10,35 \%)$ reported that other family members were similarly affected, whereas another 10 reported no other affected family members and eight did not know about the occurrence of MSL in other family members. An overview of the degree of relationship between the affected members in each family of the ten patients reporting positive family history is shown in Table 4.

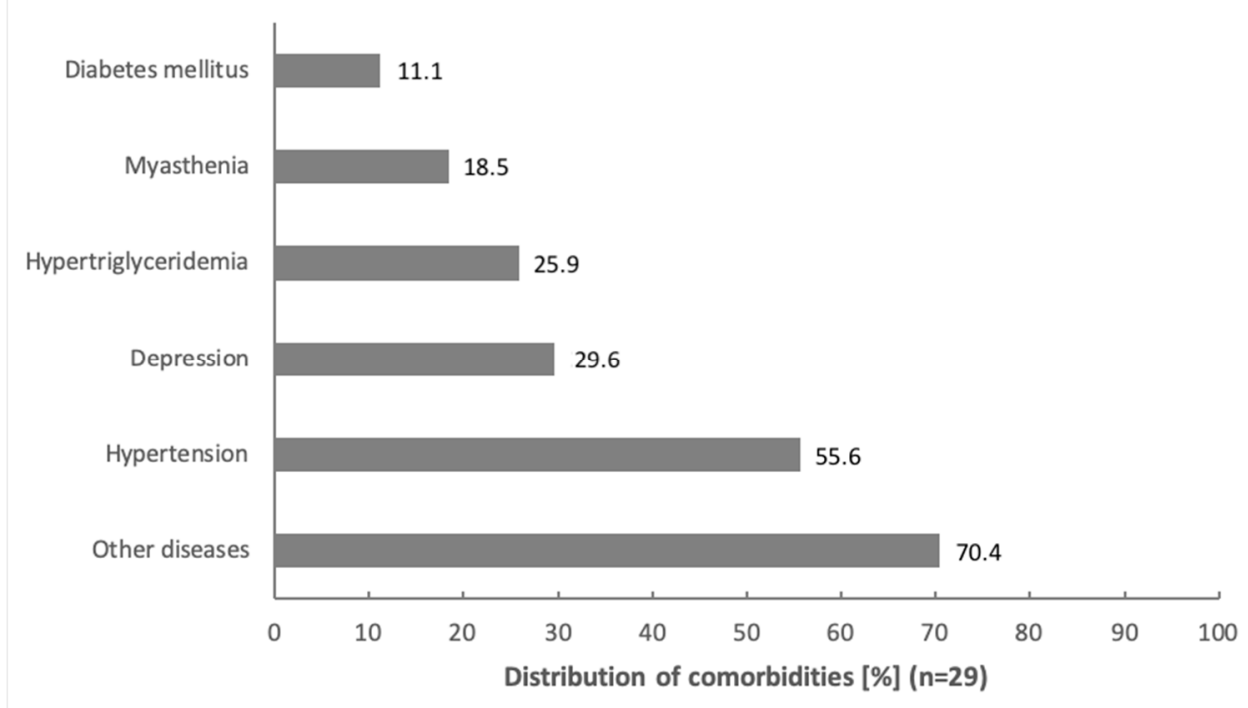

Figure 4. Distribution of comorbidities.

Table 4. Overview of MSL-affected family members in 10 patients with positive family anamnesis. (* age at assessment time).

\begin{tabular}{|c|c|c|c|c|c|c|c|c|}
\hline \multirow[b]{2}{*}{ Patient } & \multicolumn{2}{|c|}{ Relative Person 1} & \multicolumn{2}{|c|}{ Relative Person 2} & \multicolumn{2}{|c|}{ Relative Person 3} & \multicolumn{2}{|c|}{ Relative Person 4} \\
\hline & Who & Age* & Who & Age * & Who & Age * & Who & Age * \\
\hline 1 & Daughter & 25 & Daughter & 37 & Mother & & Brother & \\
\hline 2 & Sister & 25 & Mother & 40 & Uncle-maternal & & Grandmother-maternal & \\
\hline 3 & Son & 11 & Aunt & & Aunt & & Aunt & \\
\hline 4 & Grandmother & 50 & Mother & 50 & Sister & 30 & & \\
\hline 5 & Mother & & Daugther & 35 & Niece & & & \\
\hline 6 & Mother & & Grandmother & & Aunt & & & \\
\hline 7 & Sister & 40 & Mother & 40 & & & & \\
\hline 8 & Brother & 50 & & & & & & \\
\hline 9 & Brother & & & & & & & \\
\hline 10 & Father & 30 & & & & & & \\
\hline
\end{tabular}

$79 \%(n=23)$ of the patients already had surgical treatment (70\% liposuction, 30\% lipectomy). Of these 23 patients, $70 \%(n=16)$ had more than one treatment (range: $2-5$ treatments). In total $83 \%(n=24)$ of the patients wish their MSL to be treated. Of these 24 patients, $29 \%$ $(\mathrm{n}=7)$ preferred surgical treatment, $33 \%(\mathrm{n}=8)$ would prefer a treatment with drugs and $38 \%$ $(\mathrm{n}=9)$ of the patients were not sure which treatment they preferred. Treatment related data is shown in Table 2. 


\section{2. $E Q-5 D-3 L$}

Patients with MSL showed lower health states (EQ VAS Score: $\mathrm{m}=51.0, \mathrm{sd}=23.8$, range $=0-90)$ than the German Norm Population $(m=77.3)$ [30]. Additionally, patients with MSL reported more problems in all five dimensions than the German Norm Population (Figure 5).

\section{Reported problems in EQ-5D-3L dimensions [\% of any problems]}

$(n=29)$

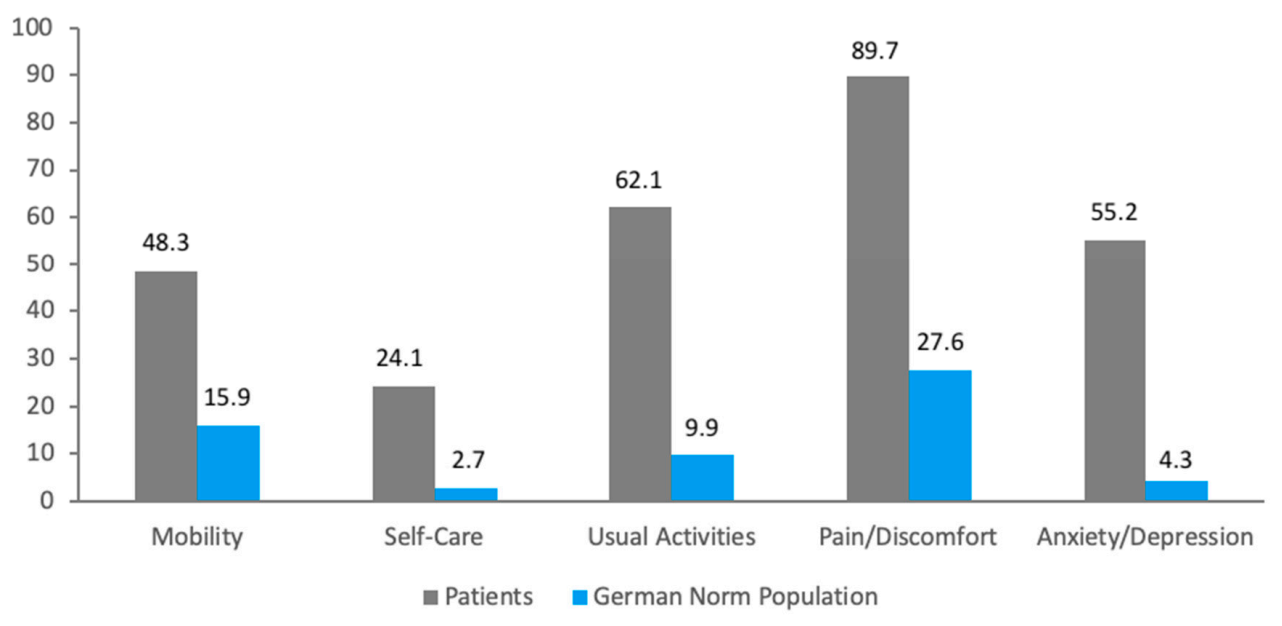

Figure 5. Responses were dichotomized in no problems (level 1) and any problems (level 2 and level 3).

\subsection{Patient-Benefit-Index-Lymphedema}

19 patients filled in the PBI-L. The weighted index values ranged from no benefit (0) to maximal benefit (4) of the therapy while values $\geq 1$ represent relevant benefit of the therapy. The mean weighted index value was $1.6(\mathrm{sd}=1.4$, range $=0-3.8)$. Thirteen patients $(68 \%)$ reported relevant benefit of the therapy and six patients $(32 \%)$ reported no benefit of the therapy.

\section{Discussion}

To our knowledge, the study was conducted on the largest current cohort of MSLaffected patients in Germany. Diagnosis was posed clinically by our research team, as there is currently no other established diagnostic tool described in the literature. The male to female ratio was 1:4, which is counter to most publications about MSL. However, a reverse male to female ratio of 1:6 was also found by Plummer et al. [31] in a series of seven patients, so the exact value of the male to female ratio and its possible determinants of variations remains an open issue. A likely explanation is that the term MSL was initially predominantly used for male patients with type Ia or type Ib MSL body type (neck and neck/shoulder girdle affection), whereas type II lipomatosis primarily affecting hips and buttocks was described by other medical terms. It remains an open question as to whether there is indeed a fundamental pathophysiological difference between different fat distribution patterns. The mean body-mass-index was $32 \mathrm{~kg} / \mathrm{m} 2$ and shows that most patients suffering from MSL are clearly overweight. Half of them indicated a weight increase in the last five years. The body areas of volume increase are typical for MSL. A statistical correlation between the areas of increased volume and patient phenotype was not possible. In order to see if volume increase primarily affects the abnormal areas of fat in MSL patients, we compared the 29 patients under study here to the 33 patients whose phenotype we investigated before (3) because these patients were all out of the same cohort of 45 MSL-patients. We compared these cohorts, assuming that compliance of these patients was high, and that most of the patients who returned the questionnaire were in the same 
cohort as the 33 patients of whom phenotype could be classified. Volume increase seems not to primarily affect the abnormal fat areas, but it appears that weight changes affect MSL patients in the same way as in both healthy and obese people. For example, only $41 \%$ of these patients were classified as type II or III, affecting the upper legs, but $92.2 \%$ of the patients reported weight gain in this region. $76 \%$ of the patients reported increase in fat deposits in the upper arms, although only $58 \%$ of the patients showed an MSL phenotype which included this area. $28 \%$ of the patients reported a trigger factor, and in two patients surgery was indicated as a potential trigger. Other trigger factors were pregnancy, oral contraceptives and liver disease (no further information), all of which have an impact on hormonal balance, especially estrogens. Estrogens are currently discussed to be involved in the pathogenesis of other subcutaneous adipose tissue diseases such as lipedema [32].

A more promising clue might be the family history. One third of the patients reported that other family members had a similar body fat distribution as them. In six families, both males and females are affected. In four families, only females are affected. Considering Table 4, this indicates a stronger heritability of the disorder than previously noted. One major general limitation in this regard is that the questionnaire item 'family history' primarily relies on the judgement of the patients who compare their medical history and body type to that of other family members. Therefore, it is possible that there is some over-reporting for this question. However, for some $(n=4)$ of the patients, affected family members MSL diagnosis could be confirmed by our team, underlining the point that familial cases are more common than generally assumed. To get valid family data and more precise information about the inheritance, detailed questions and interviews by genetic experts are required. Postulating a clear mode of inheritance is not possible from our data in all cases due to the often small size of families. Moreover, identification of a monogenic inheritance pattern is complicated by the fact that often not all affected patients could be clinically examined by our team and because disease onset is often delayed to adult age, information about many possibly affected family members is missing and many of these are already deceased or unavailable because of limitations of mobility. A clue for a monogenic factor exhibiting most likely autosomal dominant inheritance with reduced penetrance comes from a four generations family reported by us before, although we were not yet able to ascertain the underlying genetic cause [21].

There are only a few reports of familial MSL cases in the literature, but our study shows that there is a need to establish the true proportion of familial cases in future studies. For some cases the underlying causes have already been identified. Patients with a positive family history should therefore be tested for the known genetic causes, and future research should focus on identifying the underlying genetic cause(s) in MERRF-, LIPE- and MFN2-mutation-negative families.

An association with other comorbidities (e.g., hyperinsulinemia, hyperlipoproteinemia, hypothyroidism, hyperuricemia, renal tubular acidosis, neuropathy, and myopathy) has been described several times $[10,11,13,14,33]$. Comorbidities found in our study generally agree with the comorbidities found in the majority of the literature. Hypertriglyceridemia and diabetes mellitus indicate a possible link to metabolic diseases. Alcohol consumption in MSL patients is a controversial issue with a link to alcoholism often being described $[3,6,16,17]$. Data of this study showed, however, that only $14 \%$ of the patients are daily alcohol consumers, which is in line with drinking behavior of the German population [34]. Although the present findings do not support a strong alcohol/MSL interrelation, we have to be aware that alcohol consumption was assessed via self-report which may be prone to a social desirability bias.

There was no commonality concerning the medication of the patients and patients' jobs. Most patients take more than three different drugs per day, corresponding to their comorbidities. Therefore, we did not find any indication of causality between pharmaceutics or patient occupation and MSL.

Nearly all patients reported factors that increase or decrease pain, or reported paresthesia and other MSL related symptoms. However, there is no commonality in these factors. 
Warmth and cold are factors that were mentioned the most, but while some patients indicated a decrease, others reported an increase of their symptoms as a response to the same trigger. Some patients reported compression (compression stockings) would ease the pain, while others stated that it would aggravate their symptoms. Most of the patients did not mention compression at all. We therefore recommend that patients try the use of compression stockings in order to prevent further complications by secondary lymphedema.

The "EQ-5D-3L" showed that patients with MSL have lower health states than the German Norm Population and reported more problems in all five dimensions. This shows that MSL is not only a cosmetic issue, but patients also have a huge decrease in quality of life. There is a potential bias in the fact that the reduced quality of life might at least partially be related to the generally increased body mass index of the investigated population. However, to our knowledge, there are no data available about an obese German population that the results could be compared with. Prevalence of MSL has been calculated at 1:25,000 [2,3]. However, it is likely that the disorder is underdiagnosed-especially in cases where neck and shoulder girdle involvement is not as prominent as other body regions and in cases where patients credibly deny alcohol consumption. In any case, it might be a rare disease, but in view of the suffering of the patients, it deserves more public and scientific attention.

Even if $33 \%$ of the investigated patients would prefer a drug therapy, currently the only available therapies for MSL are liposuction and/or lipectomy. The PBI-L showed that liposuction and lipectomy are suitable therapies. However, a clear limitation of this study is the application of the PBI-L. The questionnaire asks about the importance of treatment goals before therapy and achievement of treatment goals post therapy and is designed for patients suffering from lymphedema. In the present study, patients retrospectively rated importance and achievement of treatment goals after treatment on one day, thus results might be biased. Another limitation of our study is that we assessed a patient cohort recruited in a clinic. One could assume that patients showing up in a clinic, and especially those presenting to a surgical department, might have a more positive attitude towards treatment in general and surgical treatment in particular. Lipectomy might be a more complete and controlled removal of MSL tissue in the sense of iatrogenic damage to nearby structures [32]. Furthermore, removed tissue can be immunohistologically examined or otherwise studied once diagnostic tools to clearly distinguish different etiologies have been developed.

This study also shows clear imitations. Since the data are based on anamnestic data, erroneous data cannot be excluded. In addition, the data refer to the subjective condition of the patients, who often do not have a medical background. Particularly with regard to other family members, the data largely refer to the patients' assessment. Future studies, assuming that MSL has a genetic component, should clinically and genetically examine the families with a positive MSL anamnesis here.

\section{Conclusions}

Patients suffering from MSL have a clear decrease in quality of life and a marked wish for treatment. Surgical treatment (liposuction/lipectomy) is a suitable therapy, although the risk of recurrence or even of triggering new adipose tissue growth remains to be assessed in a controlled study.

In some cases, MSL family history suggests a strong genetic factor, sometimes compatible with monogenic inheritance and therefore with a high recurrence risk. Alcohol consumption and MSL development has to be considered a controversial issue. A lack of history of alcohol abuse should not lead to dismissal of an MSL diagnosis.

Author Contributions: Conceptualization, L.P. and O.F. and J.S. and S.S.; methodology, S.S. and J.S. and M.K. and L.P.; formal analysis, K.M. and M.K.; investigation, C.O. and S.T. and D.S. and A.A.; resources, O.F. and S.S.; data curation, D.S. and C.O. and S.T. and A.A.; writing-original draft preparation, D.S.; writing-review and editing, D.S. and K.M. and S.S. and J.S.; visualization, D.S.; supervision, S.S.; project administration, S.S.; funding acquisition, S.S. and J.S. All authors have read and agreed to the published version of the manuscript. 
Funding: This research was funded by "Deutsche Forschungsgemeinschaft" (DFG), grant number (SCHR1513/1-1 \& SCHR1288/5-1).

Institutional Review Board Statement: The study was conducted according to the guidelines of the Declaration of Helsinki, and approved by the Institutional Ethics Committee of University of Regensburg, Germany (protocol code: 14-101-138. Date of approval: 08.01.2017).

Informed Consent Statement: Informed consent was obtained from all subjects involved in the study.

Data Availability Statement: The data presented in this study are available on request from the corresponding author. The data are not publicly available due to private police.

Conflicts of Interest: The authors declare no conflict of interest.

\section{References}

1. Enzi, G.; Busetto, L.; Ceschin, E.; Coin, A.; Digito, M.; Pigozzo, S. Multiple symmetric lipomatosis: Clinical aspects and outcome in a long-term longitudinal study. Int. J. Obes. 2002, 26, 253-261. [CrossRef]

2. Enzi, G. Multiple symmetric lipomatosis: An updated clinical report. Medicine 1984, 63, 56-64. [CrossRef]

3. Schiltz, D.; Anker, A.; Ortner, C.; Tschernitz, S.; Koller, M.; Klein, S.; Felthaus, O.; Schreml, J.; Schreml, S.; Prantl, L. Multiple Symmetric Lipomatosis: New Classification System Based on the Largest German Patient Cohort. Plast. Reconstr. Surg. Glob. Open 2018, 6, e1722. [CrossRef]

4. Enzi, G.; Busetto, L.; Sergi, G.; Coin, A.; Inelmen, E.M.; Vindigni, V.; Bassetto, F.; Cinti, S. Multiple symmetric lipomatosis: A rare disease and its possible links to brown adipose tissue. Nutr. Metab. Cardiovasc. Dis. 2015, 25, 347-353. [CrossRef]

5. Jimenez Aragon, F.; Morales Puebla, J.M.; Corzon Pereira, T. Madelung's disease. Acta Otorrinolaringol. Esp. 2013, 64, 166-167. [CrossRef]

6. Pinto, C.I.; Carvalho, P.J.; Correia, M.M. Madelung's Disease: Revision of 59 Surgical Cases. Aesthetic Plast. Surg. 2017, 41, 359-368 [CrossRef]

7. Prantl, L.; Schreml, J.; Gehmert, S.; Klein, S.; Bai, X.; Zeitler, K.; Schreml, S.; Alt, E.; Gehmert, S.; Felthaus, O. Transcription Profile in Sporadic Multiple Symmetric Lipomatosis Reveals Differential Expression at the Level of Adipose Tissue-Derived Stem Cells. Plast. Reconstr. Surg. 2016, 137, 1181-1190. [CrossRef]

8. Ruzicka, T.; Vieluf, D.; Landthaler, M.; Braun-Falco, O. Benign symmetric lipomatosis Launois-Bensaude. Report of ten cases and review of the literature. J. Am. Acad. Dermatol. 1987, 17, 663-674. [CrossRef]

9. Donhauser, G.; Vieluf, D.; Ruzicka, T.; Braun-Falco, O. Benign symmetric Launois-Bensaude type III lipomatosis and BureauBarriere syndrome. Der Hautarzt Z. Dermatol. Venerol. Verwandte Geb. 1991, 42, 311-314.

10. Brea-Garcia, B.; Cameselle-Teijeiro, J.; Couto-Gonzalez, I.; Taboada-Suarez, A.; Gonzalez-Alvarez, E. Madelung's disease: Comorbidities, fatty mass distribution, and response to treatment of 22 patients. Aesthetic Plast. Surg. 2013, 37, 409-416. [CrossRef]

11. Dorigo, P.; Prosdocimi, M.; Carpenedo, F.; Caparrotta, L.; Tessari, F.; Enzi, G. Multiple symmetric lipomatosis. A defect in adrenergic stimulated lipolysis II. Pharmacol. Res. Commun. 1980, 12, 625-638. [CrossRef]

12. Enzi, G.; Inelmen, E.M.; Baritussio, A.; Dorigo, P.; Prosdocimi, M.; Mazzoleni, F. Multiple symmetric lipomatosis: A defect in adrenergic-stimulated lipolysis. J. Clin. Investig. 1977, 60, 1221-1229. [CrossRef]

13. Gu, W.; Dou, J.; Yang, G.; Li, J.; Ba, J.; Lu, Z.; Mu, Y.; Lu, J. The endocrine and metabolic evaluation of benign symmetrical lipomatosis: A case report and literature review. Neuro Endocrinol. Lett. 2010, 31, 446-450.

14. Kan, Y.; Yao, P.; Xin, W.; Chen, Q.; Wang, J.; Yue, J.; Zhu, J. Recent progress on diagnosis and treatment of benign symmetric lipomatosis. J. Clin. Otorhinolaryngol. Head Neck Surg. 2010, 24, 105-107.

15. Lee, Y.H.; Mottillo, E.P.; Granneman, J.G. Adipose tissue plasticity from WAT to BAT and in between. Biochim. Biophys. Acta 2014, 1842, 358-369. [CrossRef]

16. Naumann, M.; Schalke, B.; Klopstock, T.; Reichmann, H.; Lange, K.W.; Wiesbeck, G.; Toyka, K.V.; Reiners, K. Neurological multisystem manifestation in multiple symmetric lipomatosis: A clinical and electrophysiological study. Muscle Nerve 1995, 18, 693-698. [CrossRef]

17. Hirose, A.; Okada, Y.; Morita, E.; Tanaka, Y. Benign symmetric lipomatosis associated with alcoholism. Intern. Med. 2006, 45, 1001-1005. [CrossRef]

18. Klopstock, T.; Naumann, M.; Schalke, B.; Bischof, F.; Seibel, P.; Kottlors, M.; Eckert, P.; Reiners, K.; Toyka, K.V.; Reichmann, H. Multiple symmetric lipomatosis: Abnormalities in complex IV and multiple deletions in mitochondrial DNA. Neurology 1994, 44, 862-866. [CrossRef]

19. Sawyer, S.L.; Cheuk-Him Ng, A.; Innes, A.M.; Wagner, J.D.; Dyment, D.A.; Tetreault, M.; Care4Rare Canada, C.; Majewski, J.; Boycott, K.M.; Screaton, R.A.; et al. Homozygous mutations in MFN2 cause multiple symmetric lipomatosis associated with neuropathy. Hum. Mol. Genet. 2015, 24, 5109-5114. [CrossRef]

20. Zolotov, S.; Xing, C.; Mahamid, R.; Shalata, A.; Sheikh-Ahmad, M.; Garg, A. Homozygous LIPE mutation in siblings with multiple symmetric lipomatosis, partial lipodystrophy, and myopathy. Am. J. Med. Genet. A 2017, 173, 190-194. [CrossRef] 
21. Lindner, A.; Marbach, F.; Tschernitz, S.; Ortner, C.; Berneburg, M.; Felthaus, O.; Prantl, L.; Kye, M.J.; Rappl, G.; Altmuller, J.; et al. Calcyphosine-like (CAPSL) is regulated in Multiple Symmetric Lipomatosis and is involved in Adipogenesis. Sci. Rep. 2019, 9, 8444. [CrossRef] [PubMed]

22. Nisoli, E.; Regianini, L.; Briscini, L.; Bulbarelli, A.; Busetto, L.; Coin, A.; Enzi, G.; Carruba, M.O. Multiple symmetric lipomatosis may be the consequence of defective noradrenergic modulation of proliferation and differentiation of brown fat cells. J. Pathol. 2002, 198, 378-387. [CrossRef]

23. Schiltz, D.; Tschernitz, S.; Ortner, C.; Anker, A.; Klein, S.; Felthaus, O.; Biermann, N.; Schreml, J.; Prantl, L.; Schreml, S. Adipose Tissue in Multiple Symmetric Lipomatosis Shows Features of Brown/Beige Fat. Aesthetic Plast. Surg. 2020. [CrossRef]

24. Felthaus, O.; Schon, T.; Schiltz, D.; Aung, T.; Kuhlmann, B.; Jung, F.; Anker, A.; Klein, S.; Prantl, L. Adipose tissue-derived stem cells from affected and unaffected areas in patients with multiple symmetric lipomatosis show differential regulation of mTOR pathway genes. Clin. Hemorheol. Microcirc. 2018, 69, 141-151. [CrossRef]

25. Statello, L.; Guo, C.J.; Chen, L.L.; Huarte, M. Gene regulation by long non-coding RNAs and its biological functions. Nat. Rev. Mol. Cell Biol. 2021, 22, 96-118. [CrossRef]

26. Greiner, W.; Claes, C.; Busschbach, J.J.; von der Schulenburg, J.M. Validating the EQ-5D with time trade off for the German population. Eur. J. Health Econ. 2005, 6, 124-130. [CrossRef]

27. EuroQol Research Foundation. EQ-5D-3L User Guide. 2018. Available online: www.euroqol.org (accessed on 13 March 2021).

28. Blome, C.; Augustin, M.; Behechtnejad, J.; Rustenbach, S.J. Dimensions of patient needs in dermatology: Subscales of the patient benefit index. Arch. Dermatol. Res. 2011, 303, 11-17. [CrossRef]

29. Blome, C.; Augustin, M.; Heyer, K.; Knofel, J.; Cornelsen, H.; Purwins, S.; Herberger, K. Evaluation of patient-relevant outcomes of lymphedema and lipedema treatment: Development and validation of a new benefit tool. Eur. J. Vasc. Endovasc. Surg. 2014, 47, 100-107. [CrossRef]

30. Szende, A.; Janssen, B. Socio-demographic indicators based on EQ-5D. In Self-Reported Population Health: An International Perspective Based on EQ-5D; Szende, A., Janssen, B., Cabases, J., Eds.; Springer: Dordrecht, The Netherlands, 2014 ; pp. 37-46. [CrossRef]

31. Plummer, C.; Spring, P.J.; Marotta, R.; Chin, J.; Taylor, G.; Sharpe, D.; Athanasou, N.A.; Thyagarajan, D.; Berkovic, S.F. Multiple Symmetrical Lipomatosis-a mitochondrial disorder of brown fat. Mitochondrion 2013, 13, 269-276. [CrossRef]

32. Herbst, K.L. Subcutaneous adipose tissue diseases: Dercum disease, lipedema, familial multiple lipomatosis, and madelung disease. In Endotext; Feingold, K.R., Anawalt, B., Boyce, A., Chrousos, G., Dungan, K., Grossman, A., Hershman, J.M., Kaltsas, G., Koch, C., Kopp, P., et al., Eds.; MDText.com, Inc.: South Dartmouth, MA, USA, 2000.

33. Lee, R.H.; Kim, B.; Choi, I.; Kim, H.; Choi, H.S.; Suh, K.; Bae, Y.C.; Jung, J.S. Characterization and expression analysis of mesenchymal stem cells from human bone marrow and adipose tissue. Cell. Physiol. Biochem. 2004, 14, 311-324. [CrossRef]

34. Schaller, K.; Kahnert, S.; Mons, U. Alkoholatlas Deutschland 2017; Deutsches Krebsforschungszentrum in der HelmholzGemeinschaft: Bonn, Germany, 2017. 